\title{
Extirpação de hemangioma em porção distal de glande peniana em cão: Relato
}

Marina Botelho Soares de Brito ${ }^{1}$, Ana Paula Rodrigues Simões ${ }^{1}$, Leandro Nassar Coutinho ${ }^{1}$, Roberto Thiesen ${ }^{2}$, Roberta Martins Crivelaro ${ }^{1}$, Marcus Antonio Rossi Feliciano ${ }^{1}$.

${ }^{1}$ Unesp-Univ Estadual Paulista "Júlio de Mesquita Filho", Faculdade de Ciências Agrárias e Veterinária (FCAV/UNESP). Jaboticabal, São Paulo. e-mail: marinabsbrito@ hotmail.com

${ }^{2}$ Universidade Federal do Pampa - UNIPAMPA. Uruguaiana, Rio Grande do Sul.

ISSUE DOI: $10.3738 / 1982.2278 .1132$

Em caninos é comum a incidência de tumores espontâneos das células endoteliais dos vasos sanguíneos, como hemangiomas e hemangiossarcomas, que são neoplasias de origem mesenquimal, provenientes de células endoteliais vasculares. Esses tumores podem se desenvolver em qualquer região corpórea, entretanto, são mais comuns na pele. Seu diagnóstico definitivo é obtido a partir de exame histopatológico, e não há relato de recidivas após excisão cirúrgica completa. Este trabalho visa relatar o caso de um cão SRD, de 4 anos, inteiro, que deu entrada no serviço de atendimento de Reprodução animal e Obstetrícia Veterinária da Faculdade de Ciências Agrárias e Veterinárias - FCAV/UNESP - Jaboticabal, apresentando sangramento peniano persistente há 6 meses. Ao exame clínico, o animal apresentou bom estado geral e uma massa hemorrágica em porção distal da glande, em região periuretral, sem obstrução do óstio. $\mathrm{O}$ animal foi sedado para realização de biópsia de fragmento da massa para exame histopatológico, cujo laudo atestou hemangioma cutâneo. Foi então realizada cirurgia para ablação testicular preventiva e extirpação da região acometida pelo tumor. Para o procedimento cirúrgico, foi realizada antissepsia do campo, colocado cateter uretral $n^{\circ} 8$ e torniquete em porção proximal do pênis, após retração do prepúcio. Com o pênis exposto, realizou-se incisão em "V" logo abaixo a massa hemorrágica, com margem mínima, para extirpação do hemangioma em sua totalidade, tomando cuidado para não lesionar a uretra e sem atingir o osso peniano. Logo após, afrouxou-se o torniquete e os vasos sanguíneos foram cauterizados, em seguida, realizou-se sutura da mucosa livre da uretra ao epitélio peniano com fio de sutura agulhado absorvível monofilamento 4-0 em padrão simples interrompido. A sonda uretral foi suturada na pele do prepúcio com padrão de sutura tipo bailarina, com fio nylon 3-0. Foi prescrito, para o pós-operatório, terapia oral com Amoxicilina com clavulanato de potássio 10/2,5 mg/kg, BID, 7 dias, Meloxicam 0,1 mg/kg, SID, 3 dias e Cloridrato de tramadol $4 \mathrm{mg} / \mathrm{kg}$, BID, 5 dias. Para uso tópico, foi prescrito limpeza da região com infusão de furacin líquido 3 vezes ao dia, durante 10 dias. Ao retorno, animal apresentava bem estar geral, e a ferida cirúrgica mostrava-se bem cicatrizada. A sonda uretral foi removida e não houve comprometimento da uretra. A cirurgia demonstrou-se simples e eficaz.

Palavras chave: neoplasia, canino, sistema reprodutor. 